\title{
Utilizing an ANP framework for prioritizing effective criteria on performance management in cooperative organization
}

\author{
Hosein Akhavan Alavi ${ }^{\mathbf{a}^{*}}$, Mostafa Alimiri ${ }^{\mathrm{b}}$ and Davood Khaleghi ${ }^{\mathrm{c}}$
} ${ }^{a}$ Assistant Professor of Public Administration, Qom Province Governor' s Office of Education and Research, Qom Province Governor' s National Elite
Foundation President and faculty of Qom, I.R.Iran
${ }^{b}$ Assistant Professor of Public Administration, Faculty of Management of Tehran Payam Noor University, Tehran, Iran
${ }^{c}$ Master of Public Management, Islamic Azad University, Arak, Iran

\begin{tabular}{|c|c|}
\hline A R T I C L E I N F O & A B S T R A C T \\
\hline $\begin{array}{l}\text { Article history: } \\
\text { Received June 28, } 2012 \\
\text { Received in Revised form } \\
\text { August, 26, } 2012 \\
\text { Accepted 29 August } 2012 \\
\text { Available online } \\
\text { 11 September } 2012 \\
\text { Keywords: } \\
\text { Performance measurement } \\
\text { Cooperative organization } \\
\text { Analytical network process }\end{array}$ & $\begin{array}{l}\text { Performance management plays an essential role on increasing efficiency of business units. It } \\
\text { helps find important barriers against a business unit helping us setup better strategies for } \\
\text { handling troubles. In this paper, we present an empirical study to find important factors } \\
\text { influencing performance management in cooperative organizations. The proposed study uses } \\
\text { analytical hierarchy process to rank important factors in three groups of team level, individual } \\
\text { and organization levels. The survey is based on receiving feedbacks from decision makers and } \\
\text { making a pairwise comparison on measuring the relative importance of each criterion } \\
\text { influencing performance management. The results of our survey indicate that setting } \\
\text { appropriate standards for performance management is the most important item followed by } \\
\text { relationship between organization structure and performance management, performance } \\
\text { management based on future events. The other three factors including continuous improvement } \\
\text { and updating systems, encouraging employee for change culture and relationship between } \\
\text { future outlook and performance management are other important factors. }\end{array}$ \\
\hline
\end{tabular}

\section{Introduction}

Performance management and measurement are important techniques in improving organizational skills. They play necessary role on increasing efficiency of business units (Neely, 2004). Performance management helps us find important barriers against a business unit helping us setup better strategies for handling troubles (Porter, 1985-2003). There are literally many efforts to find efficient methods to detect barriers in organizations. Hemati and Karkehabadi (2012), for instance, proposed a method based on integer nonlinear multiple objective programming to investigate the conditions of uncertainty in a private university in Iran using balanced scorecard method. In their implementation,

\footnotetext{
* Corresponding author.

E-mail addresses: akhavan@bmn.ir (H. Akhavan Alavi) 
In this research, they used fuzzy set covering problem and non-linear multiple objective integer programming to choose the best combination of strategies for specified period of time with the least deviation in experts' feedbacks.

\section{Theoretical Framework}

Khodaei Valahzaghard et al. (2012) performed another investigation to study the effects of human resource supporting strategies on job satisfaction. In their study, the effects of related services to support employee to reach job satisfaction and employee activities in one of Iranian banks called Mellat bank was investigated using 276 random samples. The results showed that employees were relatively satisfied from the benefit package of the bank and they were relatively happy on working for such organization.

Analytical hierarchy process (AHP) is one of the popular approaches for ranking problem with various criteria. There are several assumptions when AHP is used to make some decisions, such as, the independency between higher and lower level elements, the independency of the elements within a level, and the hierarchy structure of the decision problem (Saaty, 1994, Saaty \& Zoffer, 2011). Nevertheless, an obvious shortcoming of AHP is the primary assumption of independency among various criteria. Analytic network process (ANP), on the other hand, considers interdependencies among the decision attributes and permits a more systematic analysis. In addition, the interactions of decision attributes within the same level and the feedbacks between two various levels play important role on decision making and it must be taken into consideration during the decision making process.

Therefore, the AHP method does not properly work when we consider such decision problems (Saaty 1996). The analytical network process (ANP), as an extensive and complementary technique of the AHP, was developed by Saaty (1996; 1999; 2001; 2003; 2004; 2005; 2006; 2008). On the contrary to AHP, ANP provides a more comprehensive approach in decision-making without making other assumptions on the independency of the higher-level elements from lower-level elements and also of the elements within a level. In spite of all these issues, the applications of ANP are not very common in a decision-making problem but there has been an increase in the use of ANP in multi-criteria decision-making problems (Jharkhariaa \& Shankar , 2007).

The ANP method can be used to make decision problems, which would not be built hierarchically and does not incorporate the inner-independent and outer-independent assumptions. ANP method has been applied to diverse areas. It also gives inclusion of all the relevant criteria including tangible or intangible, etc. The ANP is the most useful model for the analysis of societal, governmental and corporate decisions that is available today to the decision makers. According to Chung et al. (2005), ANP has the following steps,

Step 1: Model construction and problem structuring: The problem needs to be stated clearly and decomposed into rational system like network. The structure can be obtained by the opinion of decision makers through brainstorming or other appropriate techniques.

Step 2: Pairwise comparisons matrices and priority vectors: In ANP, like AHP, decision elements at each component make a pairwise comparison with respect to their relative importance towards their control criteria, and the components are also compared pairwise with respect to their contribution to the objectives.

Step 3: Super matrix formation: To calculate global priorities in a system with interdependent effects, the local priority vectors are entered in the suitable columns of a matrix and a super matrix is actually a partitioned matrix, where each matrix segment denotes a relationship between two nodes (components or clusters) in a system (Sarkis 2003; Haghighat Monfared et al., 2012).

Fig. 1 shows effective factors studied for the implementation of ANP method for this survey. 


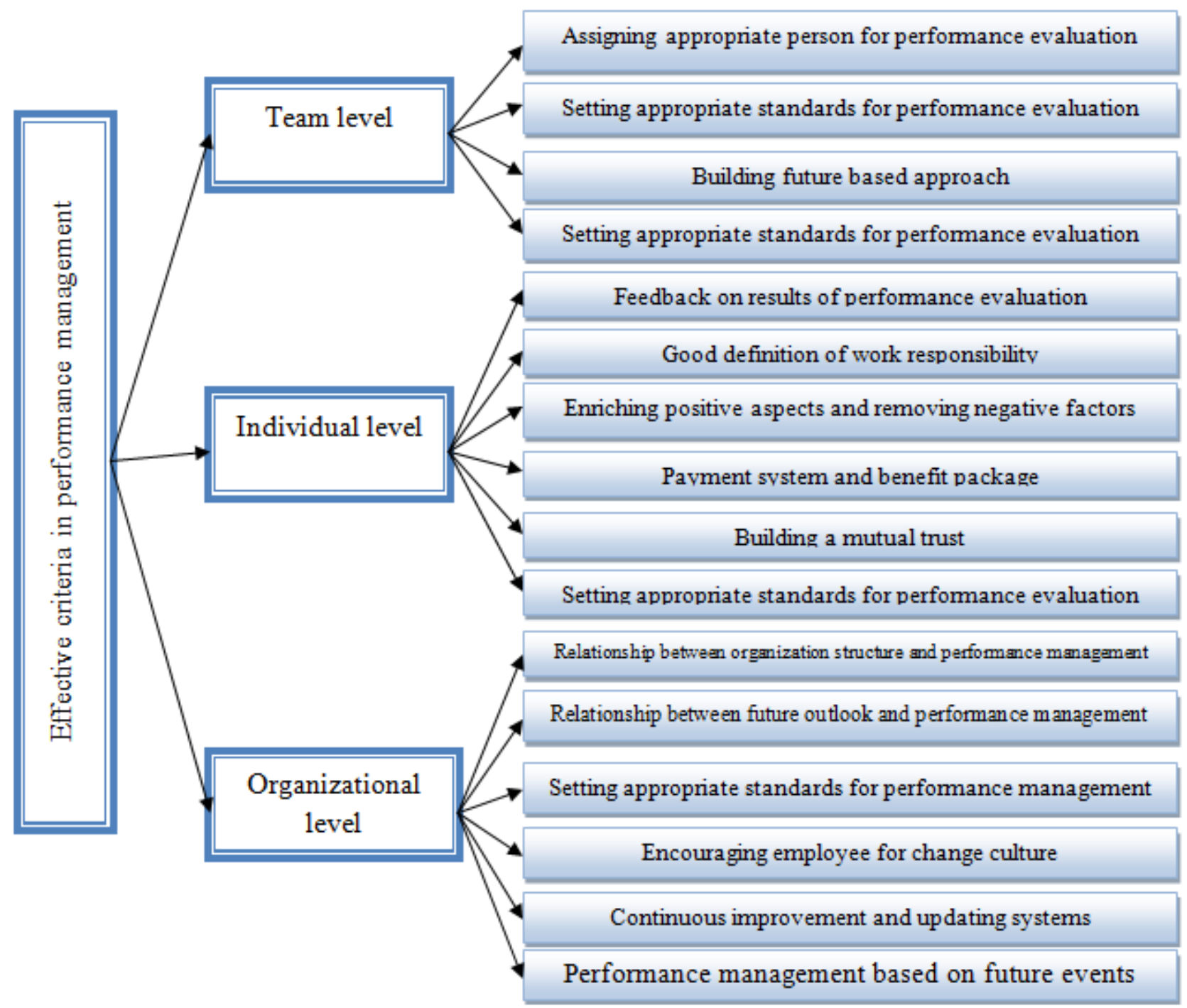

Fig. 1. Infrastructure for ANP implementation

A triangular number shown in Fig. 1 is represented as $(\mathrm{l}, \mathrm{m}, \mathrm{u})$ where $\mathrm{l}, \mathrm{m}$ and $\mathrm{u}$ represent the lowest, the most possible and the highest possible values, respectively where $l \leq m \leq \mathrm{u}$. Each fuzzy number can be represented by a membership function as follows,

$\mu(x / \widetilde{M})=\left\{\begin{array}{cc}0, & x<l, \\ (x-l) /(m-l), & l \leq x \leq m, \\ (u-x) /(u-m), & m \leq x \leq u, \\ 0, & x>u\end{array}\right.$

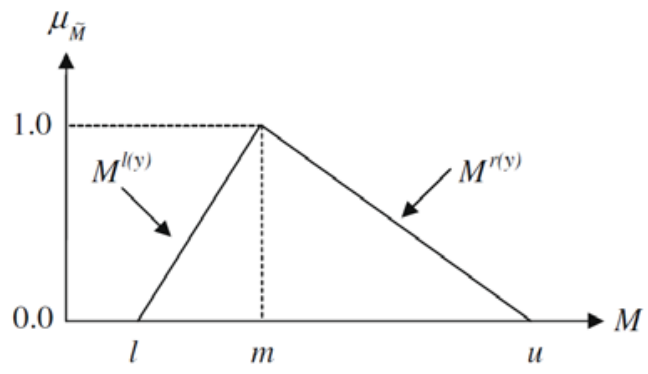

Fig.1. A triangular number 


\section{Discussion}

This paper adopts the following linguistic terms to represent a triangular fuzzy number. Table 1 shows decision making numbers in linguistic form and their equivalences.

\section{Table 1}

Lingual scale used to measure intensity of importance

\begin{tabular}{lcc}
\hline Linguistic scale & Triangular fuzzy scale & Triangular fuzzy reciprocal scale \\
\hline Strongly important & $(9,9,9)$ & $(1 / 9,1 / 9,1 / 9)$ \\
Intermediate value & $(7,8,9)$ & $(1 / 9,1 / 8,1 / 7)$ \\
Moderately important & $(6,7,8)$ & $(1 / 8,1 / 7,1 / 6)$ \\
Intermediate value & $(5,6,7)$ & $(1 / 7,1 / 6,1 / 5)$ \\
Weakly important & $(4,5,6)$ & $(1 / 6,1 / 5,1 / 4)$ \\
Intermediate value & $(3,4,5)$ & $(1 / 5,1 / 4,1 / 3)$ \\
Equally important & $(2,3,4)$ & $(1 / 4,1 / 3,1 / 2)$ \\
Intermediate value & $(1,2,3)$ & $(1 / 3,1 / 2,1 / 1)$ \\
Just equal & $(1,1,1)$ & $(1,1,1)$ \\
\hline
\end{tabular}

\section{Table 2}

Final ranking of performance measurement characteristics in team level

\begin{tabular}{lllll}
\hline Character & $\mathrm{a}_{\mathrm{l}}$ & $\mathrm{a}_{\mathrm{m}}$ & $\mathrm{a}_{\mathrm{u}}$ & Rank \\
\hline Assigning appropriate person for performance evaluation & 0.35 & 0.59 & 0.94 & 2 \\
Setting appropriate standards for performance evaluation & 0.48 & 0.72 & 0.97 & 1 \\
Building future based approach & 0.16 & 0.29 & 0.49 & 4 \\
Target setting for performance management system & 0.24 & 0.38 & 0.67 & 3 \\
\hline
\end{tabular}

As we can observe from the results of Table 2, setting appropriate standards for performance evaluation is the most important factor for the success of performance measurement in team level followed by assigning appropriate person for performance evaluation. Target setting for performance measurement system is the third important factor and finally building future based approach is the last important option in implementation of fuzzy ANP system.

\section{Table 3}

Final ranking of performance management characteristics in individual level

\begin{tabular}{lllll}
\hline Character & $\mathrm{a}_{\mathrm{l}}$ & $\mathrm{a}_{\mathrm{m}}$ & $\mathrm{a}_{\mathrm{u}}$ & Rank \\
\hline Feedback on results of performance evaluation & 0.31 & 0.53 & 0.82 & 3 \\
Good definition of work responsibility & 0.63 & 0.87 & 0.96 & 1 \\
Enriching positive aspects and removing negative factors & 0.13 & 0.21 & 0.37 & 6 \\
Payment system and benefit package & 0.24 & 0.41 & 0.61 & 4 \\
Building a mutual trust & 0.22 & 0.37 & 0.59 & 5 \\
Setting appropriate standards for performance evaluation & 0.49 & 0.75 & 0.89 & 2 \\
\hline
\end{tabular}

According to the results of Table 3, in terms of performance management in individual level, good definition of work responsibility is the most important item followed by setting appropriate standards for performance evaluation. Having constructive feedback on performance evaluation is another important factor in individual level while payment system and benefit package also pay important role on performance management. Finally, building a mutual trust among individuals as well as 
enriching positive aspects of performance evaluation and removing any undesirable factors are the last important factors influencing performance management.

\section{Table 4}

Final ranking of performance management characteristics in organizational level

\begin{tabular}{|c|c|c|c|c|}
\hline Character & $\mathrm{a}_{1}$ & $\mathrm{a}_{\mathrm{m}}$ & $\mathrm{a}_{\mathrm{u}}$ & Rank \\
\hline Relationship between organization structure and performance management & 0.52 & 0.72 & 0.88 & 2 \\
\hline Relationship between future outlook and performance management & 0.07 & 0.21 & 0.33 & 6 \\
\hline Setting appropriate standards for performance management & 0.73 & 0.85 & 0.92 & 1 \\
\hline Encouraging employee for change culture & 0.17 & 0.29 & 0.44 & 5 \\
\hline Continuous improvement and updating systems & 0.24 & 0.39 & 0.57 & 4 \\
\hline Performance management based on future events & 0.36 & 0.54 & 0.76 & 3 \\
\hline
\end{tabular}

As we can observe from the results of Table 4, setting appropriate standards for performance management is the most important item followed by relationship between organization structure and performance management, performance management based on future events. The other three factors including continuous improvement and updating systems, encouraging employee for change culture and relationship between future outlook and performance management are other important factors.

\section{Conclusion}

In this paper, we have presented an empirical study to find important factors influencing performance management in cooperative organizations. The proposed study used analytical hierarchy process to rank important factors in three groups of team level, individual and organization levels. We have used the feedback received from experts to make a pairwise comparison on measuring the relative importance of each criterion influencing performance management. The results of our survey indicate that setting appropriate standards for performance management is the most important item followed by relationship between organization structure and performance management, performance management based on future events. The other three factors including continuous improvement and updating systems, encouraging employee for change culture and relationship between future outlook and performance management are other important factors.

\section{References}

Chung, S.H., Lee, A.H.I., \& Pearn, W.L. (2005). Analytic network process (ANP) approach for product mix planning in semiconductor fabricator. International Journal of Production Economics, 96 (1), 15-36.

Jharkharia, S., \& Shankar, R. (2007). Selection of logistics service provider: an analytic network process (ANP) approach. Omega 35, 274-289.

Khodaei Valahzaghard, M., Afzali, F., \& Khodaei Valahzaghard, S.(2012). An empirical study on the effects of human resource supporting strategies on job satisfaction. Management Science Letters, 2, 1535-1542.

Haghighat Monfared, J., Jannatifar, H. and Siahkali Moradi, J. (2012). Utilizing an ANP framework for prioritizing effective criteria on industrial clusters' formation. Management Science Letters, 2(2), 571-578.

Hemati, M., \& Karkehabadi, H. (2012). Presenting an algorithm of integer nonlinear multiple objective programming in conditions of uncertainty for balanced scorecard method (case study in Islamic Azad University, Semnan Branch). Management Science Letters, 2, 1305-1316.

Neely, A. (2004). Business Performance Measurement: Theory and Practice. Cambridge University.

Porter, M.E. (1985). Competitive Advantage, Macmillan, New York, Free Press.

Porter, M.E. (1990). The Competitive Advantage of Nations. New York: Basic Books.

Porter, M.E. (1995). Competitive Advantage of the Inner City. Harvard Business Review, 55-71. 
Porter, M.E. (1997). New strategies for Inner city economic. Development, Economic Development Quarterly, 11(1), 11-27.

Porter, M.E. (1998). Clusters and the New Economic of Competition. Harvard Business Review (November / December).

Porter, M. E. (2001) Clusters of Innovation: Regional Foundations of U.S. Competitiveness, Council on Competitiveness, Washington, Dc .Super Discussion Paper No. 00-39.

Porter, M.E, (2003a). The Economic Performance of Regions. Regional Studies, 37(6-7), 549-678.

Porter, M.E, (2003b). Building the Microeconomic Foundations of Competitiveness. in the Global Competitiveness Report 2002-2003, World Economic Forum, New York: Oxford University Press.

Saaty, T.L. (1994). Fundamentals of the Analytic Hierarchy Process. RWS Publications, 4922 Ellsworth Ave., Pittsburgh, Pennsylvania.

Saaty, T.L. (1996). Decision Making with Dependence and Feedback: The Analytic Network Process. Pittsburgh, Pennsylvania: RWS Publications. ISBN 0-9620317-9-8.

Saaty, T.L. (1999). Fundamentals of the analytic network process. ISAHP 1999, Kobe, Japan, August 12-14.

Saaty, T.L. (2001). Decision making with the analytic network process (ANP) and its Super Decisions Software: The National Missile Defense (NMD) Example, ISAHP 2001 Proceedings, Bern, Switzerland, August, 2-4.

Saaty, T.L. (2004). Fundamentals of the analytic network process: Dependence and feedback in decision-making with a single network. Journal of Systems Science and Systems Engineering, published at Tsinghua University, Beijing, Vol. 13, No. 2, pp. 129-157.

Saaty, T.L. (2005). Theory and Applications of the Analytic Network Process: Decision Making with Benefits, Opportunities, Costs and Risks. Pittsburgh, Pennsylvania: RWS Publications. ISBN 1888603-06-2.

Saaty, T.L. (2006). Rank from Comparisons and from Ratings in the Analytic Hierarchy/ Network Processes. European Journal of Operational Research, 168, 557-570.

Saaty, T.L. (2008). The Analytic Network Process. Iranian Journal of Operations Research, 1(1), 127.

Sarkis, J. (2003). Quantitative models for performance measurement systems alternate considerations. International Journal of Production Economics. 86 (1), 81-90. 